\title{
A Hybrid Grey Relational Analysis and Nondominated Sorting Genetic Algorithm-II for Project Portfolio Selection
}

\author{
Farshad Faezy Razi \\ Department of Industrial Management, Islamic Azad University, Semnan Branch, Semnan, Iran \\ Correspondence should be addressed to Farshad Faezy Razi; farshadfaezy@gmail.com
}

Received 27 June 2014; Revised 24 November 2014; Accepted 30 November 2014; Published 24 December 2014

Academic Editor: Konstantina Skouri

Copyright (c) 2014 Farshad Faezy Razi. This is an open access article distributed under the Creative Commons Attribution License, which permits unrestricted use, distribution, and reproduction in any medium, provided the original work is properly cited.

\begin{abstract}
Project selection and formation of an optimal portfolio of selected projects are among the main challenges of project management. For this purpose, several factors and indicators are simultaneously examined considering the terms and conditions of the decision problem. Obviously, both qualitative and quantitative factors may influence the formation of a portfolio of projects. In this study, the projects were first ranked using grey relational analysis to form an optimal portfolio of projects and to create an expert system for the final project selection. Because of the fuzzy nature of the environmental risk of each project, the environmental risk was predicted and analyzed using the fuzzy inference system and failure mode and effect analysis based on fuzzy rules. Then, the rank and risk of each project were optimized using a two-objective zero-one mathematical programming model considering the practical constraints of the decision problem through the nondominated sorting genetic algorithm-II (NSGA-II). A case study was used to discuss the practical methodology for selecting a portfolio of projects.
\end{abstract}

\section{Introduction}

Project selection is among important issues in industrial management, industrial engineering, and governmental, nonprofit, and commercial organizations [1]. The selection of the best portfolio or project to achieve full satisfaction in an organization has been considered in previous studies [2]. The project selection process can be defined as follows: it is started by continuous collecting, analyzing, and judging the available information on the project leading to project selection considering the factors influencing the selection process [3]. The project portfolio selection is a multicriteria decision problem which considers multicriteria quantitative and qualitative factors simultaneously [4]. In the multicriteria decision-making model, the solution may already exist and therefore the purpose is to select the best solution from the available solution set. This class of decision problems is called multicriteria decision models. On the other hand, the solution may be unknown. In this case, the purpose is to find the optimal Pareto solution of the problem in the continuous or discrete space [5]. Such decision models are called multiple objective decision-making models. The multicriteria decision models are formed based on utility theory and human pressures in dealing with the behavior of max finder [6]. In 1945, John Newman published his famous book Theory of Games and Economic Behavior and proposed a mathematical theory for game theory-based economic and social organizations. This provided the ground for developing multiple attribute decision-making (MADM) models in the decision theory [7]. In general, MADM models are designed based on one of the philosophical approaches of choice, rank, description, sort, design, and portfolio [8]. In this study, the choice, rank, and design approaches were combined to form a portfolio of projects. According to this approach, the projects were ranked through the grey relational analysis in MADM literature. Then, the environmental risk of the project was analyzed and predicted by a fuzzy inference system. Thereafter, a twoobjective zero-one mathematical programming model was designed to optimize the risk and rank of each project considering the constraints governing the optimal decision problem and the design philosophy in the multiple objective decisionmaking literature. The Pareto solution of the model was obtained using the nondominated sorting genetic algorithmII (NSGA-II). The paper proceeds as follows: the literature 
is reviewed in Section 2. Section 3 examines the grey relational analysis method. Fuzzy inference system is described in Section 4. NSGA-II is introduced in Section 5. A new approach for selecting the portfolio of projects is presented in Section 6. A case study and conclusions are presented in Sections 7 and 8, respectively.

\section{Literature Review}

Zarei et al. (2009) developed an expert system for portfolio selection. The proposed system analyzed the technical risk and return on investment. In this model, the preferences are weighted and then the optimal portfolio is clustered through the rough set theory [9]. Lin and Liu proposed a portfolio optimization model based on Markowitz linear programming model for project portfolio selection using the minimum swap size. The optimal Pareto solution of the model was obtained by a genetic algorithm [10]. Doerner et al. presented a multiobjective integer programming model for optimal portfolio selection using the ant colony optimization algorithm [11]. Martínez-Lorente et al. considered both qualitative and quantitative objectives to optimize the portfolio of projects. In this study, the path analysis was used to analyze the qualitative objectives [12]. Bilbao-Terol et al. considered the social responsibility to select the optimal portfolio. In this approach, enterprises do not invest in activities neglecting ethical standards. Obviously, the portfolio is completed through the assets observing the ethical standards. For this purpose, a measure called social responsibility attractiveness was used [13]. Eshlaghy and Razi proposed a $k$-mean algorithm-based grey relational analysis model for project portfolio selection. In this model, the projects are first clustered through the $k$-mean algorithm; then, each cluster is ranked using the grey relational analysis. Finally, the Pareto solutions of rank and risk are analyzed by the genetic algorithm [14]. In another study, Razi et al. clustered projects using the $C$-mean fuzzy algorithm and then analyzed the clusters using the grey relational analysis. In this study, the project risk analysis was carried out through a fuzzy inference system [15]. Huang et al. designed a model based on the semivariance index to invest in a portfolio of real estate assets considering the risk preference to optimize the portfolio of real estate assets. In the second stage, the Pareto optimal solution of the model was analyzed using the bee colony algorithm. The modeling approach in this study is based on the salesman network model [16].

\section{Grey Relational Analysis}

In 1982, Deng published the first paper on the grey system theory entitled "The Control of the Grey Systems" and then the grey system theory was introduced [17]. Briefly, the basic idea of grey theory is as follows: the overall picture of the system is imagined considering the partial or limited information about a system. This methodology deals with uncertain, incomplete, and poor problems. As one of the main features of the grey system theory, this theory can provide satisfactory outputs using relatively low information and the high variability in the criteria. Like the fuzzy theory, the grey theory is an effective mathematical model for solving uncertain and ambiguous problems [18]. There are many different systems in the real world; each of them has its own components and subsystems. To recognize a system, the relations between the components as well as the structure of the system should be identified in addition to understanding the components. If the completely known and unknown information of a system is, respectively, shown by white and black colors, the information on most systems in nature is not white (well known) or black (unknown), but it is a mixture of both colors, that is, grey information. Such systems are called grey systems. The main characteristic of grey systems is incomplete information. The aim of the grey systems theory and its applications is to create a bridge between the social sciences and natural sciences. Grey color means the deficiency of information and uncertainty [19]. The grey relational analysis includes the following steps.

Formation of a Grey Relation. When the performance measurement units for different indicators are different, it is likely that the effects of some parameters are ignored. Furthermore, when some performance indicators have a wide range, this may happen. In addition, the performance indicators with different objectives or directions may lead to inaccurate results. Thus, it is necessary to convert all performance values of an alternative to comparative series through a process similar to normalization process. In grey systems theory, this process is called the formation of grey relations. In a multicriteria decision-making problem with $m$ alternatives and $n$ indexes, the $i$ th alternative is shown by $y_{i}=\left(y_{i 1}, y_{i 2}, \ldots\right.$, $\left.y_{i j}, \ldots, y_{i n}\right)$ in which $y_{i j}$ is the performance value of the index $j$ for the alternative $i . y_{i}$ can be converted into the comparative series $x_{i}=\left(x_{i 1}, x_{i 2}, \ldots x_{i j}, \ldots, x_{i n}\right)$ using one of the following equations:

$$
\begin{aligned}
X_{i}(j)^{*} & =\frac{x_{i}(j)-\min x_{i}(j)}{\max x_{i}(j)-\min x_{i}(j)}, \\
X_{i}(j)^{*} & =\frac{\max x_{i}(j)-x_{i}(j)}{\max x_{i}(j)-\min x_{i}(j)}, \\
X_{i j} & =\frac{\left|x_{i}(j)-x_{0 b}(j)\right|}{\max x_{i}(j)-x_{0 b}(j)} .
\end{aligned}
$$

Equation (1) is used for "the bigger, the better" indexes while (2) is used for "the smaller, the better" indexes. Equation (3) is used for the case where "values closer to the optimal value of $y_{j}^{*}$ are better" [20].

The Reference Target Series. Once the grey relations were formed using (1), (2), or (3), all performance values are located in the range $[0,1]$. In the case where the value of $x_{i j}$ generated by the grey relation creation process is equal to 1 or closer to 1 than the value of any alternative, the performance of the index $i$ in the alternative $j$ is better than other alternatives. Thus, the alternative for which all performance values are equal to 1 is the best alternative. In this study, the reference series is defined as $x_{0}=\left(x_{01}, x_{02}, \ldots, x_{0 j}\right.$, $\left.\ldots, x_{0 n}\right)=(1,1, \ldots, 1, \ldots, 1)$. Accordingly, it searches for 
an alternative whose comparative series is closer to this target series [21].

Grey Relational Coefficient. The grey relational coefficient is used to determine the proximity of $x_{i j}$ to $x_{0 j}$. Higher grey relational coefficient, closer $x_{i j}$ to $x_{0 j}$. The grey relational coefficient is calculated using (4), where $Y\left(x_{0 j}, x_{i j}\right)$ represents the gray relational coefficient between $x_{i j}$ and $x_{0 j}$. The coefficient of determination is used to expand or limit the domain of the grey relational coefficient [22]

$$
\begin{gathered}
Y\left(x_{0 j}, x_{i j}\right)=\frac{\Delta_{\min +\xi} \Delta_{\max }}{\Delta_{i j+\xi} \Delta_{\max }}, \\
\Delta_{i j}=x_{0 j}-x_{i j} .
\end{gathered}
$$

Grey Relational Rank. Once all grey relational coefficients, $Y\left(x_{0 j}, x_{i j}\right)$, were calculated, the grey relational rank can be calculated using

$$
\Gamma\left(x_{0}, x_{i}\right)=\sum_{j=1}^{n} w_{j} \cdot Y\left(x_{0 j}, x_{i j}\right) .
$$

Equation (5) represents the grey relational rank, $\Gamma\left(x_{0}, x_{i}\right)$, between $x_{i}$ and $x_{0}$. In fact, (5) shows the correlation between the reference target series and the comparative series in which $w_{j}$ is the weight of index $j . w_{i}$ is usually dependent on the judgment of the decision-maker or the structure of problem. In addition, $\sum_{j=1}^{n} w_{j}=1$. As mentioned earlier, the reference series shows the best achievable performance of each index in the comparative series. Therefore, the comparative series with the highest grey relational rank with the reference series has the highest similarity with the reference target series. Thus, this is the best choice [23].

\section{Fuzzy Inference System}

Fuzzy inference system provides a systematic process to convert a knowledge base to a nonlinear mapping. This is why the knowledge-based systems (fuzzy systems) are used in engineering and decision-making applications [24]. Mamdani and Assilian used fuzzy inference systems to control a steam engine and boiler combination using a combination of linguistic control rules and the experience of human operators [25]. A fuzzy system has the following components:

(i) a fuzzifier to convert the numerical values of the variables into a fuzzy set,

(ii) a fuzzy rules base as a set of "if then" rules,

(iii) a fuzzy inference engine to convert inputs to outputs through a series of actions,

(iv) a defuzzifier to convert the fuzzy output into a crisp number [26].

In this study, the fuzzy inference system described in Figure 1 is used to analyze the environmental risk for each project. As shown in Figure 1, the factors constituting the environmental

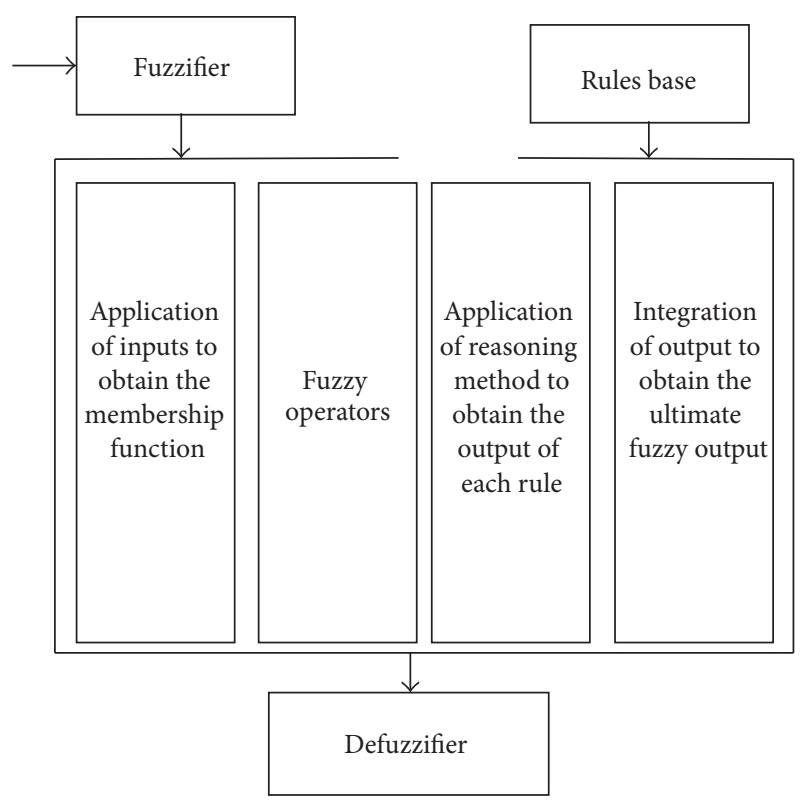

FIGURE 1: A fuzzy inference system for environmental risk analysis of each project.

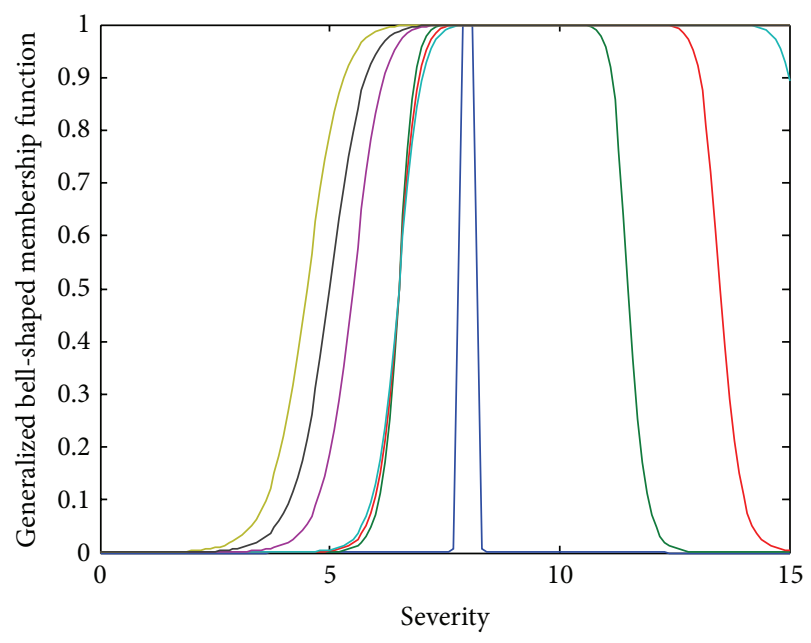

FIGURE 2: Generalized bell-shaped membership function for Severity.

risk of each project are analyzed by failure mode and effect analysis based on three factors, $\mathrm{S}, \mathrm{O}$, and $\mathrm{D}$.

As shown in Figures 2, 3, and 4, the fuzzy membership functions of Severity, Occurrence, and Detection are generalized bell-shaped membership function, triangular-shaped membership function, and Gaussian curve membership function, respectively.

It should be noted that the traditional approach of failure mode and effect analysis (FMEA) employs Risk Priority Number (RPN) for prioritization of failure modes using (6). RPN is the product of Severity, Occurrence, and Detection [27]:

$$
\text { RPN }=\text { Severity } \times \text { Occurrence } \times \text { Detection } .
$$




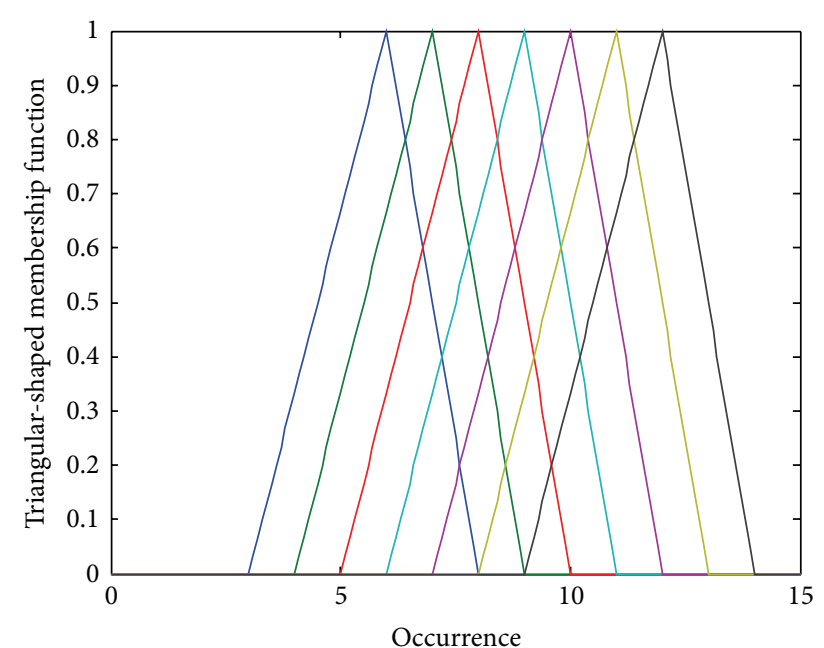

FIGURE 3: Triangular-shaped membership for Occurrence.

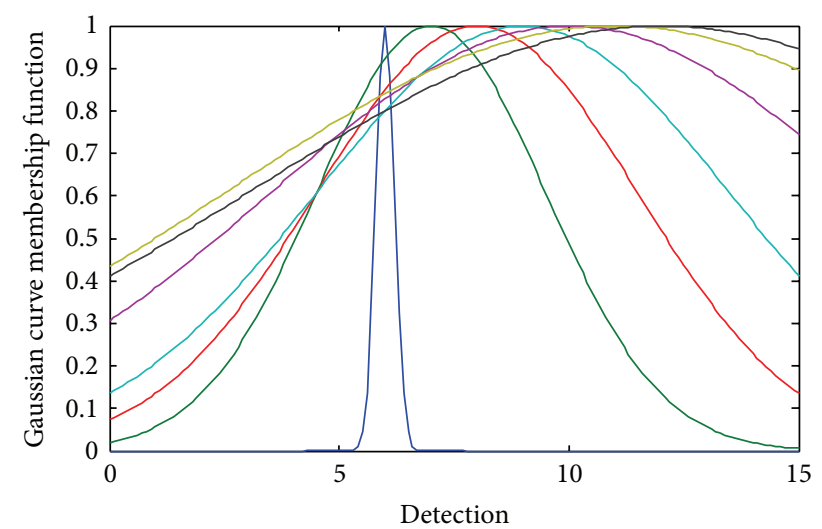

FIGURE 4: Gaussian curve membership function for Detection.

The fuzzy output of RPN is presented as a triangular-shaped membership in Figure 5.

\section{NSGA-II}

Genetic algorithm (GA) is a probabilistic search method inspired by the natural process of biological evolution. GA operates on a population of potential solutions. This algorithm is used for NP-hard problems [28]. The general NSGAII algorithm is as follows:

(i) population initialization;

(ii) fitness calculation;

(iii) sorting the population according to dominant conditions;

(iv) crowding distance;

(v) selection: once the initial population was sorted based on dominant conditions, the crowding distance will be calculated and the selection of the initial population is started. The selection is done based on the two following elements:

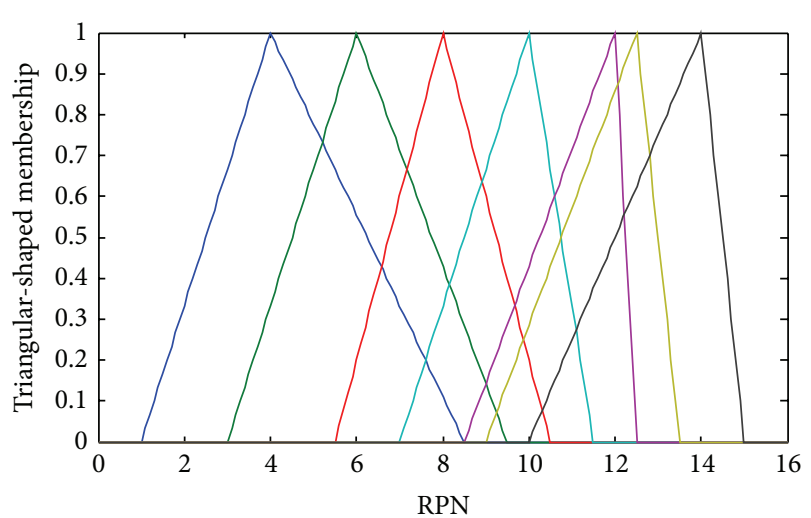

FiguRE 5: Triangular-shaped membership for environmental risk.

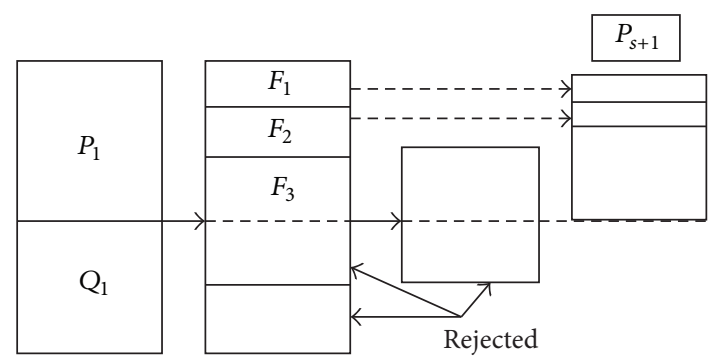

FIGURE 6: Sorting population using NSGA-II algorithm.

population rank: the lower-rank populations are selected;

distance calculation: if $p$ and $q$ are two members of the same rank, a member with the largest crowding distance is selected; it should be noted that the selection is first done based on the rank and then the crowding distance;

(vi) crossover and mutation operations to produce new offspring: this is done using a binary selection technique;

(vii) integration of the initial population and the population obtained from the crossover and mutation operations.

To replace the parents with the best members of the combined population in the previous stages, at the first stage, the lower-rank members are replaced with previous parents and then are sorted according to the crowding distance. This process is summarized in Figure 6. As shown in Figure 6, the initial population and population generated by crossover and mutation operations are categorized based on the rank. Then, the lower-rank population is deleted. In the next stage, the remaining population is sorted according to crowding distance. Here, sorting is done within a front and all stages are repeated to reach the target generation (or optimality conditions) [29]. In Figure 6, $P$ and $Q$ are the initial population and the population from crossover and mutation operations, respectively. $F_{i}$ represents the front. 


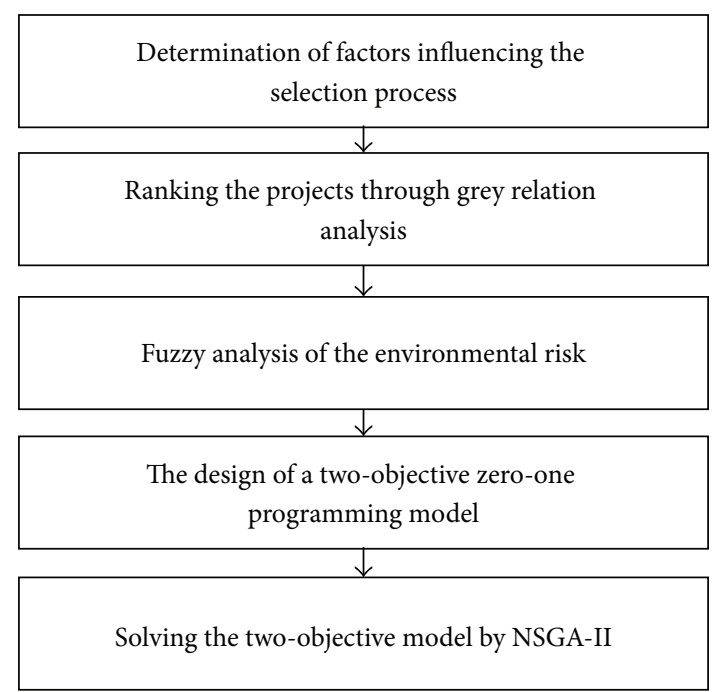

FIGURE 7: Project selection by the hybrid algorithm of grey relational analysis and nondominated sorting genetic algorithm-II.

\section{A New Framework for Project Portfolio Selection}

This section describes a hybrid algorithm of grey relational analysis and the nondominated sorting genetic algorithm-II. The main stages of the framework presented in this paper are summarized in Figure 7.

As shown in Figure 7, the parameters affecting the selection and formation of a set of projects are first determined. Then, the selected projects are ranked by grey relational analysis to form an initial portfolio of projects. Thereafter, the environmental risk of each project is analyzed through fuzzy inference system based on failure mode and effect analysis. Then, a two-objective zero-one programming model is designed to optimize the risk and rank. The limitations include budget constraints, staffing, independence, and dependence of projects. The two-objective model determines the optimal Pareto solutions of risk and rank using NSGA-II algorithm.

\section{Case Study}

In this section, a case study is presented for project portfolio selection using hybrid grey relational analysis and nondominated sorting genetic algorithm-II. Table 1 shows the input data. Among the six criteria for twenty projects, "the bigger, the better" criteria include earnings per project (EP), the impact of the project on the economic prosperity of the region (EPE), the impact of the project on the social boom of the region (SPE), the number of personnel employed in each project (MP), and the years during which the project is used without significant reconstruction costs (UP). The operating costs (CP) of each project are a criterion of "the smaller, the better" type.

The ranking results of grey relational analysis are presented in Table 2 and Figure 8.
TABLE 1: The input data for project selection.

\begin{tabular}{lcccccc}
\hline Project & EP & EPE & SPE & MP & UP & CP \\
\hline PP1 & 2285 & 9 & 4 & 776 & 14 & 450 \\
PP2 & 1561 & 9 & 9 & 884 & 10 & 599 \\
PP3 & 1374 & 8 & 9 & 639 & 15 & 502 \\
PP4 & 2745 & 4 & 8 & 845 & 13 & 382 \\
PP5 & 1648 & 3 & 1 & 532 & 10 & 678 \\
PP6 & 1634 & 5 & 1 & 555 & 15 & 567 \\
PP7 & 1244 & 3 & 4 & 858 & 13 & 565 \\
PP8 & 1199 & 7 & 2 & 504 & 10 & 539 \\
PP9 & 2510 & 3 & 3 & 720 & 10 & 528 \\
PP10 & 1581 & 5 & 7 & 531 & 14 & 460 \\
PP11 & 1043 & 8 & 4 & 649 & 12 & 647 \\
PP12 & 2729 & 2 & 5 & 527 & 15 & 522 \\
PP13 & 2475 & 3 & 7 & 678 & 11 & 402 \\
PP14 & 2021 & 2 & 9 & 838 & 12 & 630 \\
PP15 & 2097 & 2 & 4 & 709 & 13 & 669 \\
PP16 & 2934 & 4 & 10 & 902 & 13 & 408 \\
PP17 & 1148 & 8 & 7 & 923 & 13 & 407 \\
PP18 & 1471 & 7 & 7 & 593 & 13 & 439 \\
PP19 & 2525 & 7 & 1 & 716 & 10 & 495 \\
PP20 & 2719 & 10 & 6 & 764 & 11 & 605 \\
\hline
\end{tabular}

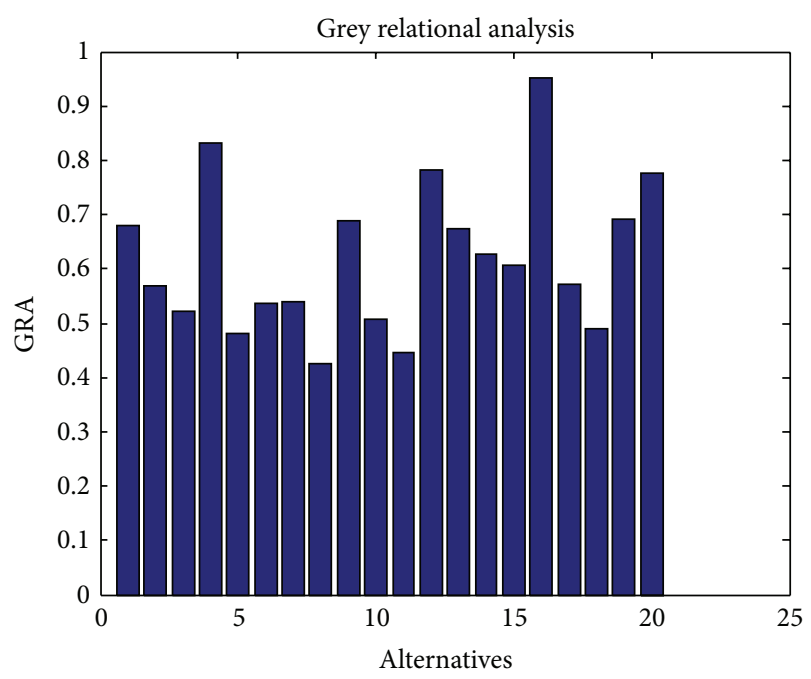

FIGURE 8: Results of grey relational analysis.

The fuzzy inference system was used to analyze the environmental risk of the project according to the discussion provided in Section 4. Figure 9 shows the environmental risk for the first project.

The two-objective programming model for twenty projects is presented as Model (7). This model maximizes the rank of each project while minimizing the environmental risk given the constraints of the problem:

$\operatorname{Max}$

$$
\begin{aligned}
z_{1}= & -0.6799 x_{1}-0.5698 x_{2}-0.5215 x_{3} \\
& +0.8333 x_{4}+0.4810 x_{5}-0.5372 x_{6}
\end{aligned}
$$


TABLE 2: The degree of grey relation for the studied projects.

\begin{tabular}{lccccccccccc}
\hline Project & 1 & 2 & 3 & 4 & 5 & 6 & 7 & 8 & 9 & 10 \\
\hline GRA & 0.6799 & 0.5698 & 0.5215 & 0.8333 & 0.4810 & 0.5372 & 0.5396 & 0.4268 & 0.6880 & 0.5070 \\
\hline Project & 11 & 12 & 13 & 14 & 15 & 16 & 17 & 18 & 19 & 20 \\
\hline GRA & 0.4473 & 0.7815 & 0.6734 & 0.6267 & 0.6067 & 0.9506 & 0.5706 & 0.4899 & 0.6918 & 0.7777 \\
\hline
\end{tabular}

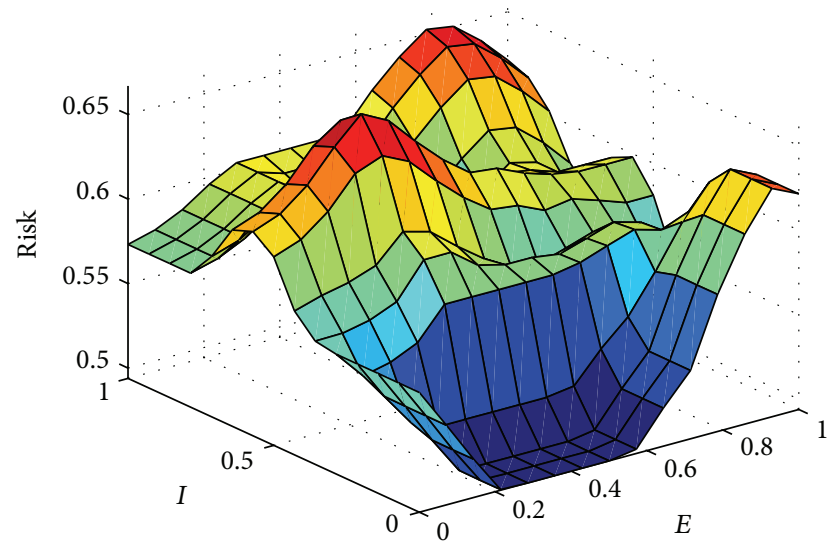

FIGURE 9: The environmental risk of the first project obtained by the fuzzy inference system.

$$
\begin{aligned}
& +0.5396 x_{7}+0.4268 x_{8}+0.6880 x_{9} \\
& +0.5070 x_{10}-0.4473 x_{11}+0.7815 x_{12} \\
& -0.6734 x_{13}-0.6267 x_{14}+0.6067 x_{15} \\
& -0.9506 x_{16}-0.5706 x_{17}-0.4899 x_{18} \\
& +0.6918 x_{19}-0.7777 x_{20}
\end{aligned}
$$

$\operatorname{Min}$

$$
\begin{aligned}
z_{2}= & 0.61 x_{1}-0.532 x_{2}+0.243 x_{3}-0.752 x_{4} \\
& -0.539 x_{5}-0.547 x_{6}+0.338 x_{7} \\
& -0.821 x_{8}-0.673 x_{9}+0.924 x_{10} \\
& +0.432 x_{11}-0.532 x_{12}+0.724 x_{13} \\
& -0.327 x_{14}+0.876 x_{15}+0.143 x_{16} \\
& +0.185 x_{17}-0.442 x_{18}+0.646 x_{19} \\
& +0.175 x_{20}
\end{aligned}
$$

subject to: $\quad 0.3 x_{1}+0.2 x_{2}+0.4 x_{3}+0.35 x_{4}+0.22 x_{5}$

$$
\begin{gathered}
+0.35 x_{6}+0.29 x_{7}+0.24 x_{8}+0.33 x_{9} \\
+0.3 x_{10}+0.3 x_{11}+0.2 x_{12}+0.31 x_{13} \\
+0.32 x_{14}+0.32 x_{15}+0.34 x_{16}+0.38 x_{17} \\
+0.27 x_{18}+0.37 x_{19}+0.25 x_{20} \leq 4 \\
776 x_{1}+884 x_{2}+639 x_{3}+845 x_{4}+532 x_{5} \\
+555 x_{6}+858 x_{7}+504 x_{8}+720 x_{9}
\end{gathered}
$$

TABLE 3: The Pareto solution combination.

\begin{tabular}{lc}
\hline$Z_{1}$ & $Z_{2}$ \\
\hline-7.7505 & 4.8860 \\
-6.8753 & 6.5700 \\
-7.2267 & 5.5640 \\
-7.4242 & 5.0580 \\
-6.9004 & 5.7360 \\
\hline
\end{tabular}

$$
\begin{aligned}
& +531 x_{10}+649 x_{11}+527 x_{12}+678 x_{13} \\
& +838 x_{14}+709 x_{15}+902 x_{16}+923 x_{17} \\
& +593 x_{18}+716 x_{19}+764 x_{20} \geq 5000, \\
& x_{13}+x_{20} \leq 1 \\
& x_{11}+x_{18} \leq 1, \\
& x_{4}-x_{8} \leq 0, \\
& x_{2}-x_{9} \leq 0, \\
& x j \in[0 \text { or } 1], \quad j=1,2,3, \ldots, 20 .
\end{aligned}
$$

In Model (7), the first and second objective functions represent the risk and rank of each project, respectively. The first and second constraints are related to funding and staffing for each project, respectively. The third to sixth constraints are related to the selection of independent and dependent projects given the reasonable constraints. Figure 10 shows the optimal Pareto solutions of the risk and rank of Model (7) obtained from the multiobjective genetic algorithm.

The algorithm execution time is 22.783 seconds. Table 3 shows the Pareto solution combination.

\section{Conclusions}

The selection of a portfolio from a large number of potential projects can be modeled as a hybrid model including metaheuristic algorithms and multicriteria decision-making techniques. In such circumstances, the criteria governing the decision problem could be a combination of qualitative and quantitative criteria. Therefore, such decision problems are inherently complex and ambiguous. In this study, the following approach was proposed to select a portfolio of projects.

(i) The grey relational analysis was used to rank the candidate projects.

(ii) The hybrid failure analysis model and the fuzzy inference system were used to analyze and predict the risk of project portfolio. 


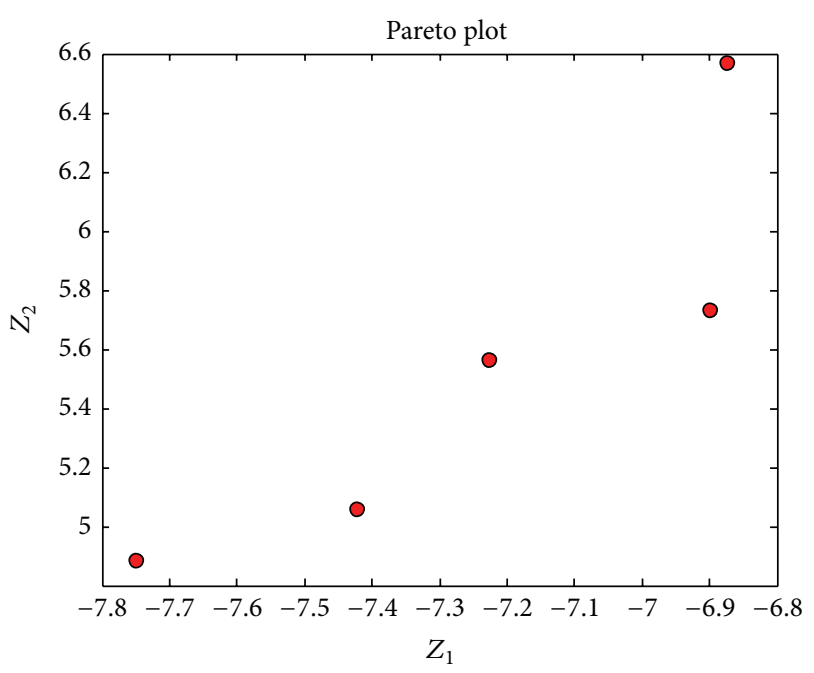

Figure 10: Pareto front of rank and risk.

(iii) The environmental protection and green project management were considered in multicriteria project selection.

(iv) According to the literature on the optimal Pareto solutions of risk and rank, the metaheuristic NSGAII algorithm was used to select the optimal Pareto combination.

\section{Conflict of Interests}

The author declares that there is no conflict of interests regarding the publication of this paper.

\section{References}

[1] D. L. Hall and A. Nauda, "An interactive approach for selecting IR\&D projects," IEEE Transactions on Engineering Management, vol. 37, no. 2, pp. 126-133, 1990.

[2] J. Wang, Y. Xu, and Z. Li, "Research on project selection system of pre-evaluation of engineering design project bidding," International Journal of Project Management, vol. 27, no. 6, pp. 584-599, 2009.

[3] A. Lund, N. Gorden, and A. Altounian, Anaheim Bid User's Guide, Anaheim Technologies Inc., Montreal, Canada, 1989.

[4] J. F. Bard, R. Balachandra, and P. E. Kaufmann, "Interactive approach to R\&D project selection and termination," IEEE Transactions on Engineering Management, vol. 35, no. 3, pp. 139146, 1988.

[5] M. Ehrgott, Multicriteria Optimization, vol. 2, Springer, New York, NY, USA, 2005.

[6] G.-H. Tzeng and J.-J. Huang, Multiple Attribute Decision Making: Methods and Applications, CRC Press, Boca Raton, Fla, USA, 2011.

[7] S.-J. Chen and C.-L. Hwang, Fuzzy Multiple Attribute Decision Making, vol. 375 of Lecture Notes in Economics and Mathematical Systems, Springer, Berlin, Germany, 1992.

[8] A. Ishizaka and P. Nemery, Multi-criteria Decision Analysis: Methods and Software, John Wiley \& Sons, New York, NY, USA, 2013.
[9] H. Zarei, M. F. Zarandi, and M. Karbasian, A New Fuzzy DSS/ES for Stock Portfolio Selection Using Technical andFundamental Approaches in Parallel.

[10] C.-C. Lin and Y.-T. Liu, "Genetic algorithms for portfolio selection problems with minimum transaction lots," European Journal of Operational Research, vol. 185, no. 1, pp. 393-404, 2008.

[11] K. Doerner, W. J. Gutjahr, R. F. Hartl, C. Strauss, and C. Stummer, "Pareto ant colony optimization: a metaheuristic approach to multiobjective portfolio selection," Annals of Operations Research, vol. 131, no. 1-4, pp. 79-99, 2004.

[12] A. R. Martínez-Lorente, F. Dewhurst, and B. G. Dale, "Total quality management: origins and evolution of the term," TQM Magazine, vol. 10, no. 5, pp. 378-386, 1998.

[13] A. Bilbao-Terol, M. Arenas-Parra, and V. Cañal-Fernández, "Selection of socially responsible portfolios using goal programming and fuzzy technology," Information Sciences, vol. 189, pp. 110-125, 2012.

[14] A. T. Eshlaghy and F. F. Razi, "A hybrid grey-based K-means and genetic algorithm for project selection," International Journal of Business Information Systems, vol. 19, no. 2, 2015.

[15] A. T. E. F. F. Razi, J. Nazemi, M. Alborzi, and A. Poorebrahimi, "A hybrid grey based fuzzy C-means and multiple objective genetic algorithms for project portfolio selection," International Journal of Industrial and Systems Engineering. In press.

[16] D. Huang, S. Zhu, F. J. Fabozzi, and M. Fukushima, "Portfolio selection under distributional uncertainty: a relative robust CVaR approach," European Journal of Operational Research, vol. 203, no. 1, pp. 185-194, 2010.

[17] J. L. Deng, "Introduction to grey system theory," The Journal of Grey System, vol. 1, no. 1, pp. 1-24, 1989.

[18] C.-C. Yang and B.-S. Chen, "Supplier selection using combined analytical hierarchy process and grey relational analysis," Journal of Manufacturing Technology Management, vol. 17, no. 7, pp. 926-941, 2006.

[19] K.-H. Chang, Y.-C. Chang, and I.-T. Tsai, "Enhancing FMEA assessment by integrating grey relational analysis and the decision making trial and evaluation laboratory approach," Engineering Failure Analysis, vol. 31, pp. 211-224, 2013.

[20] P. Mujumdar and S. Karmakar, "Grey fuzzy multi-objective optimization," in Fuzzy Multi-Criteria Decision Making, pp. 453-482, Springer, 2008.

[21] Y. Kuo, T. Yang, and G.-W. Huang, “The use of grey relational analysis in solving multiple attribute decision-making problems," Computers \& Industrial Engineering, vol. 55, no. 1, pp. 8093, 2008.

[22] Z. Li, D. Zhang, and Q. Gao, "A grey method of prioritizing engineering characteristics in QFD," in Proceedings of the Chinese Control and Decision Conference (CCDC '09), pp. 34433447, IEEE, 2009.

[23] P. Wang, P. Meng, J.-Y. Zhai, and Z.-Q. Zhu, "A hybrid method using experiment design and grey relational analysis for multiple criteria decision making problems," Knowledge-Based Systems, vol. 53, pp. 100-107, 2013.

[24] J.-S. R. Jang, "ANFIS: adaptive-network-based fuzzy inference system," IEEE Transactions on Systems, Man and Cybernetics, vol. 23, no. 3, pp. 665-685, 1993.

[25] E. H. Mamdani and S. Assilian, "An experiment in linguistic synthesis with a fuzzy logic controller," International Journal of Man-Machine Studies, vol. 7, no. 1, pp. 1-13, 1975. 
[26] N. K. Kasabov and Q. Song, "DENFIS: dynamic evolving neural-fuzzy inference system and its application for time-series prediction," IEEE Transactions on Fuzzy Systems, vol. 10, no. 2, pp. 144-154, 2002.

[27] H.-T. Liu and Y.-L. Tsai, "A fuzzy risk assessment approach for occupational hazards in the construction industry," Safety Science, vol. 50, no. 4, pp. 1067-1078, 2012.

[28] E. G. Bekele and J. W. Nicklow, "Multi-objective automatic calibration of SWAT using NSGA-II," Journal of Hydrology, vol. 341, no. 3-4, pp. 165-176, 2007.

[29] C. A. C. Coello, D. A. van Veldhuizen, and G. B. Lamont, Evolutionary Algorithms for Solving Multi-Objective Problems, vol. 242, Springer, 2002. 


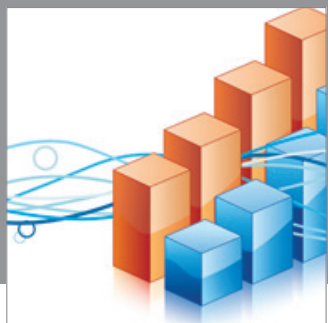

Advances in

Operations Research

mansans

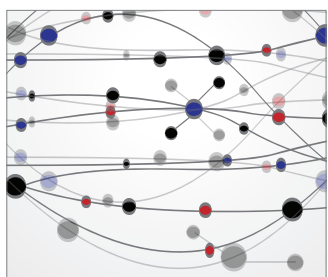

The Scientific World Journal
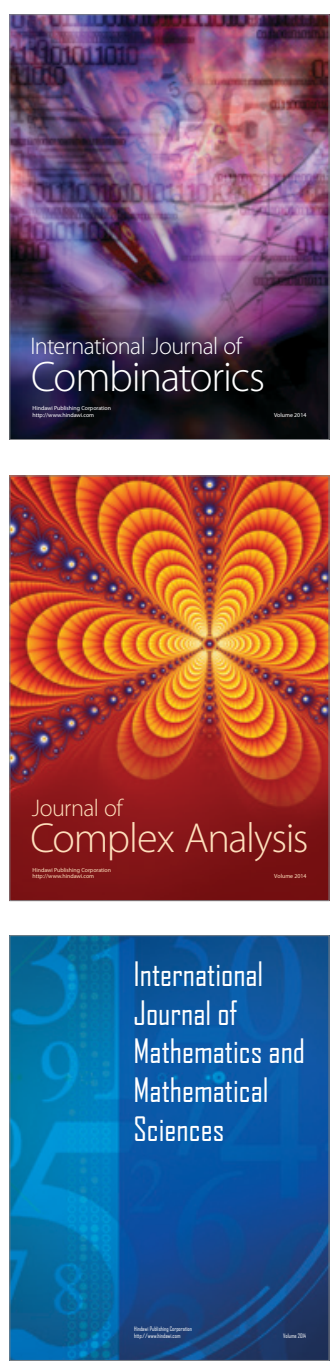
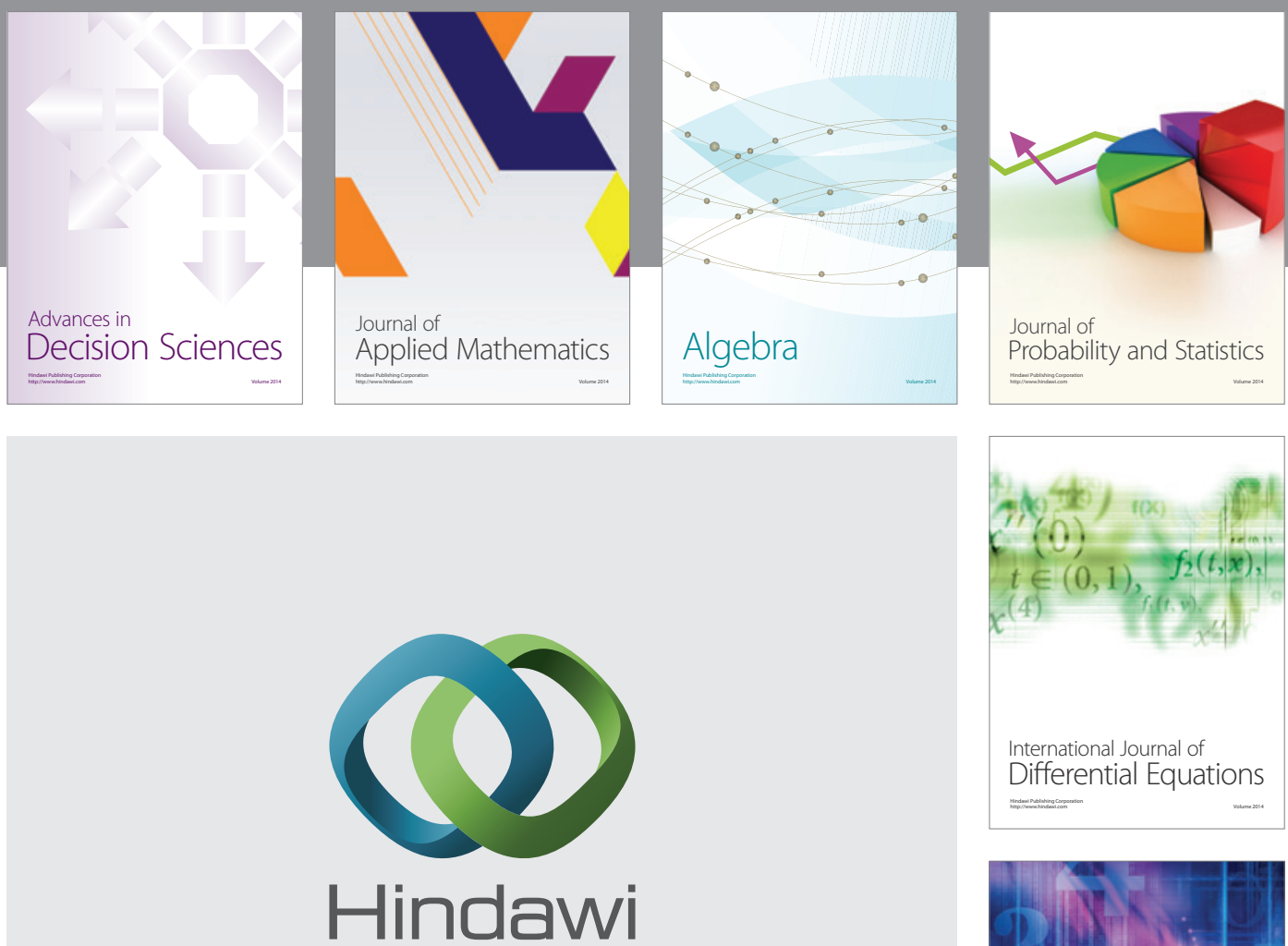

Submit your manuscripts at http://www.hindawi.com
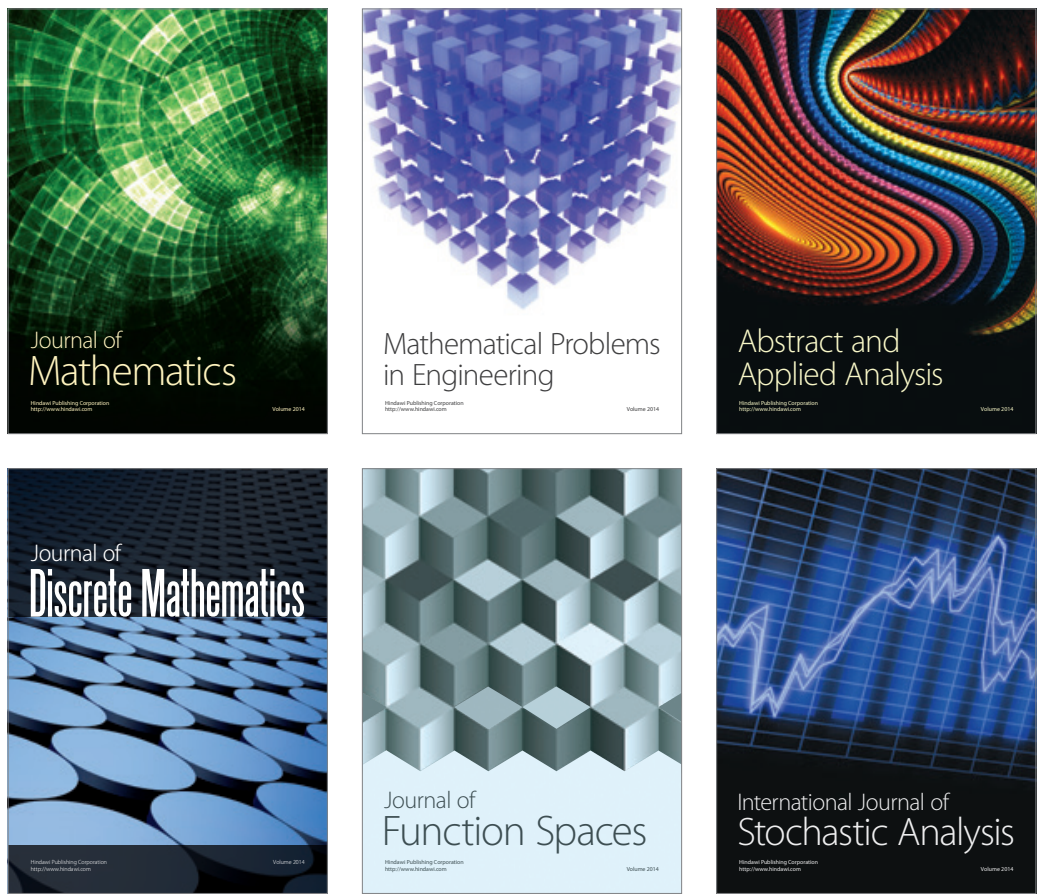

Journal of

Function Spaces

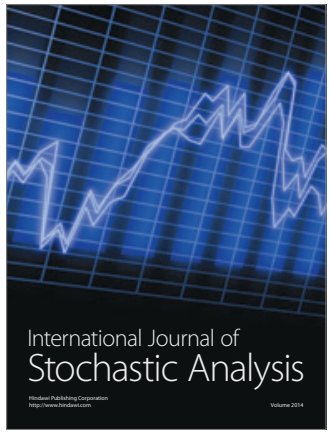

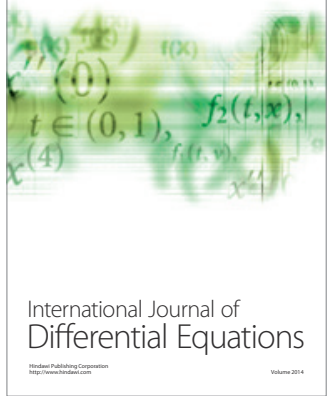
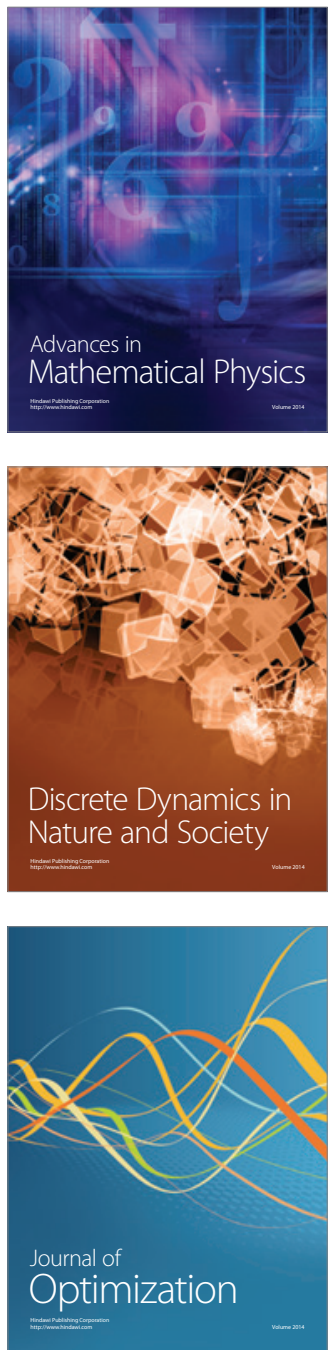